\title{
Development and Verification of Auditory Training Tool for Children
}

\author{
Jae In Lee ${ }^{1,2}$, Junghwa Bahng ${ }^{2}$, Jae Hee Lee ${ }^{2}$ \\ 'Department of Otorhinolaryngology-Head and Neck Surgery, Hallym University College of Medicine, Anyang, Korea \\ ${ }^{2}$ Department of Audiology, Hallym University of Graduate Studies, Seoul, Korea
}

아동용 청능훈련 도구의 개발 및 검증

이재인 ${ }^{1,2} \cdot$ 방정화 $^{2} \cdot$ 이재희 ${ }^{2}$

한림대학교 성심병원 이비인후과 ${ }^{1}$, 한림국제대학원대학교 청각학과 ${ }^{2}$

\begin{abstract}
Purpose: Despite various options of auditory training materials for hearing-impaired adults, auditory training tool has been relatively limited for hearing-impaired children. Given that closed-set auditory training would adjust the level of difficulty easier, the purpose of this study was to develop multiple-choice sentences as a closed-set auditory training material for hearing-impaired children. Methods: The sentences were recorded by a professional female speaker, and the keywords in each recorded sentence were cut and re-synthesized. Using the keywords, we constructed six sentence lists (list 1 for practice, list 2-6 for training). Each sentence included 2-4 keywords such as name, adjective, object, numeral, and verb. In total, 1,616 sentences were generated from any possible combination of words. Pictures matching the key words in sentence were also made by a professional illustrator. As a final step, 25 preschool children with normal hearing participated in determining the difficulty level of training material at $0,3,6 \mathrm{~dB}$ signal-to-noise ratio (SNR) conditions. Results: Results showed that the multiple-choice sentences developed in this study were identified with the mean accuracy greater than $96 \%$ for list $1-5$, regardless of noise conditions. However, the mean sentence recognition score of list 6 was $34-44 \%$ for the conditions of 0,3 , $6 \mathrm{~dB}$ SNRs. The sentence recognition score of list 6 was not related to the age of children. Conclusion: The developed multiple-choice sentences could be used as the auditory-training material for children. Continued research is necessary to determine the clinical feasibility of this auditory training tool for preschool hearing-impaired children.
\end{abstract}

Key Words: Auditory training tool for children, Auditory rehabilitation, Hearing-impaired children.

Received: February 9, 2017 / Revised: March 23, 2017 / Accepted: March 24, 2017

Correspondence: Jae Hee Lee, Department of Audiology, Hallym University of Graduate Studies, 427 Yeoksam-ro, Gangnam-gu, Seoul 06198, Korea Tel: +82-2-2051-4952 / Fax: +82-2-3451-6618 / E-mail: leejaehee@hallym.ac.kr

\section{INTRODUCTION}

2012년 세계보건기구는 전 세계 난청인의 수가 약 3억 5,000 만 명이고, 이 중 약 9\%인 3,200만 명이 유소아 난청이라 보고 하였다. 2002년에 미국 질병예방통제센터는 100 명의 어린이 중 12 명이 소음성 난청의 위험에 노출되어 있다고 발표한 바 있다. 난청 아동의 수가 점차 증가함에 따라 난청의 조기 발견 및 청 능재활의 중요성이 강조되었다. 난청이 의심되는 경우 조기에 난청을 진단받고 청력 손실의 종류와 정도에 따라 적절한 증폭 기기를 착용하는 등 청각재활을 최대한 빨리 시작하는 것이 중 요하다. 청능훈련은 청능재활의 중요한 요소 중 하나로, 반복적 인 듣기 연습을 통한 의사소통 능력 개선을 목표로 하는 것이
다. 청능훈련은 단순히 듣기 능력만을 향상시키는 것이 아니라 청각 기능을 포함하여 인지, 기억 및 주의집중 발달에도 긍정적 인 영향을 미칠 수 있다(Ferguson \& Henshaw, 2015; Henshaw \& Ferguson, 2013; Oh, 2016). 아동의 경우 조기에 적극적이고 집중적인 청능훈련을 시작하여야 말, 언어, 의사소통 능력 발달 에 있어서의 문제점을 최소화할 수 있다(Kim \& Yoon, 2016; Lee, 2016; Yoon et al., 2016).

국외에서는 아동을 대상으로 소프트웨어를 이용하는 청능훈 련 프로그램을 개발하거나 환경음, 어음, 소음, 음악 등의 다양 한 자극음을 사용하여 훈련 효과를 입증한 연구가 다수 보고 되었다(Cameron \& Dillon, 2011; Ingvalson et al., 2014; Loo et al., 2016; Melo et al., 2015; Rochette \& Bigand, 2009; Ro- 
chette et al., 2014; Sullivan et al., 2013; Talebi et al., 2015). 국 내의 경우 환경음(Ahn \& Lee, 2016), 4 6 어절 문장(Chang \& Lee, 2016), 선다형 문장(Lee et al., 2016b), 가로세로 단어판 (Baek \& Lee, 2016), 이야기(Lim \& Bahng, 2016) 등을 활용 하는 다양한 청능훈련 도구가 개발되었으나, 이는 대부분 성인 을 대상으로 개발한 청능훈련 도구들이다. 인공와우 착용 아동 을 대상으로 한 음악을 이용한 청능훈련의 효과를 보고한 국내 연구가 있으나(Choi et al., 2017; Oh, 2016; Seo \& Lim, 2007) 아 동용 청능훈련 프로그램의 개발은 여전히 부족한 실정이다(YoO \& Lee, 2011; Yoon \& Hwang, 2005).

본 연구에서는 아동이 흥미를 가지고 청능훈련에 참여할 수 있도록 문장을 듣고 그림 보기에서 문장 내 단어를 고르는 (closed-set) 청능훈련 도구를 제작하였다. 훈련 시 난이도 조 절이 가능하게 하기 위해 2 4개의 중심 단어를 포함하는 문장 목록을 구성하였고, 아동의 듣기 능력에 따라 소음 없는 조건 혹은 0, 3, $6 \mathrm{~dB}$ 의 신호대잡음비(signal-to-noise ratio, SNR)에 서 청능훈련이 가능하도록 음원을 제작하였다. 예비 실험을 통 해 최종 문장 음원과 그림판의 적절성을 확인한 후, 학령전기 건청 아동을 대상으로 소음 하에서 문장 음원을 제시하여 훈 련 도구의 난이도를 검증하였다.

\section{MATERIALS AND METHODS}

아동용 청능훈련 도구의 개발 및 검증을 위해 아래의 순서 로(1 5단계) 연구를 진행하였다. 단계별 연구 절차를 요약하면 다음과 같다. 먼저, 학령전기 아동의 어휘에 관한 문헌에서 단 어를 수집한 후 6 개의 문장 목록을 구성하였고(1단계), 전문 성 우를 통해 문장 음원을 녹음하고 편집하여 총 1,616개의 문장 음원을 제작하였다. 아동의 듣기 능력에 따라 소음 하 훈련이 필요할 수 있으므로 4가지 조건(소음 없는 상황과 $0,3,6 \mathrm{~dB}$ $\mathrm{SNR}$ )에서 훈련이 가능하도록 모든 문장 음원을 어음스펙트럼 소음과 믹싱하였다(2단계). 아동이 문장을 듣고 문장 내 단어 에 해당하는 그림을 고를 수 있도록 전문 일러스트레이터를 통 해 그림판을 제작하였다(3단계). 4 명의 아동을 대상으로 한 예 비 실험을 통해 문장 음원의 자연성 및 그림판의 적절성을 확 인하였고(4단계), 수정이 필요한 경우 음원을 재녹음하거나 그 림판을 재제작하였다. 마지막으로 건청 아동 25명을 대상으로 소음 하에서 훈련 도구를 제시하고 문장인지도 측정을 통해 도 구의 난이도를 검증하였다(5단계).

\section{연구 절차}

\section{1단계: 단어 수집 및 문장 목록 구성}

학령전기 아동이 듣고 이해 가능한 훈련 도구를 개발하기 위 해 유소아 및 초등 저학년의 어휘(Chang et al., 2013, 2014), 유 소아용 문헌 등을 이용하여 단어를 수집하였다. 위의 선행 연 구 자료 중 학령전기 아동에게 친숙한 “명사, 동사, 수사"의 단 어를 위주로 1 차 수집하였고, 의미 영역별로 “행위, 상태, 사물, 음식, 사람, 신체, 장소, 동물, 의류, 탈 것”의 단어를 2차 수집하 였다. 그 외에 유소아용 문헌인 "어린이 한글 사전, 기초지식 어 린이 백과사전, 동식물백과” 등을 이용하여 유소아 고빈도 어 휘를 3차 수집하였다. 기타 선행연구(Cha et al., 2014; Oh et al., 2014)의 연령별 언어 발달의 특징을 고려하여 학령전기 아 동에게 친숙한 총 114 개의 단어를 선정하고 해당 단어를 포함 하는 문장을 구성하였다. 문장 구성 시 문법적 구조와 문장의 자연성 등을 고려하였으며, list 1 4에서는 현재형 동사 시제를, list 5 에서는 과거형을 사용하였다.

훈련 시 난이도 조절이 용이하게 하기 위해 각 목록당 서로 다른 개수의 중심 단어(key word)가 포함되게 하였고, 연령별 아동의 작업기억 능력(Igualada et al., 2017)을 참고하여 최소 $3 \sim 5$ 개의 단어를 포함하는 문장 목록을 구성하였다. Appendix 1은 list 1 6의 문장 예시와 문장 내 중심 단어(key words)들 을 보여준다. List 1 은 훈련 전 이해를 돕기 위해 사용하는 연습 (practice) 목록이었고, list 2 5는 훈련용 문장 목록이었다. 예 를 들어 list 2 의 경우 동물을 지칭하는 8 개의 중심 단어(염소, 기린, 타조, 두더지, 병아리, 소, 여우, 얼룩말)와 탈 것을 지칭하 는 8개의(자동차, 배, 기차, 자전거, 비행기, 미끄럼틀, 그네, 시 소) 중심 단어가 있으므로 64 개 $(8 \times 8)$ 의 문장 생성이 가능하 였다. List 3 의 경우 24 개의 중심 단어(8개의 동물, 8 개의 색깔, 8 개의 숫자 $)$ 의 조합으로 총 512 개 $(8 \times 8 \times 8)$ 의 문장을 구성 하는 것이 가능하였고, list 6 의 경우 20개의 중심 단어(5개의 주어, 5 개의 장소, 10 개의 물건 $)$ 의 조합으로 625 개 $(5 \times 5 \times 5$ $\times 5)$ 의 문장 생성이 가능하였다.

\section{2단계: 음원 녹음 및 편집}

본 연구의 음원 녹음을 위해 현재 성우로 활동하고 있는 전 문가가 참여하였다. 전문 음향 녹음 무음실에서 문장 녹음을 진 행하였고, 녹음 시 Neumann TLM (Georg Neumann GmbH, Berlin, Germany) 마이크로폰, Apogee PSX-100 (Apogee Electronics Corp., Santa Monica, CA, USA) analog to digital converter, Mac-Book Pro (Apple Inc., Cupertino, CA, USA) 를 사용하였다. 녹음을 하는 동안 화자에게 마이크와 입 간 거 리를 유지하고 보통 대화 속도와 크기로 녹음할 것을 요청하였 
다. 녹음된 문장 음원을 디지털로 변환하여 각각 저장하였고, Adobe Audition CC 2015 (Adobe System Inc., San Jose, CA, $\mathrm{USA}$ ) 소프트웨어를 사용하여 문장 음원 내 단어들을 각각 잘 라내어 별도의 파일로 저장한 후 각 단어 음원의 실효값(root mean square)이 동일하도록 $( \pm 1 \mathrm{~dB})$ 조절한 후 단어들을 조합 하였다. 단어 조합 시 문장의 자연성을 위해서 문장이 시작되 기 전과 문장이 끝난 후 부분의 간격을 $0.4 \mathrm{msec}$, 단어와 단어 간의 간격을 $0.2 \mathrm{msec}$ 로 설정하였다.

Appendix 1에 표기하였듯이 목록에 따라 문장 내 중심 단 어들을 조합하여 생성 가능한 문장 수가 서로 달랐다(list 1: 문장 8개, list 2: 64개, list 3: 512개, list 4: 64개, list 5: 343개, list 6: 625개). 문장 목록(list 1 6)을 모두 합하여 문장 음원 총 1,616 개를 제작하였고, 이를 한국어 어음스펙트럼을 가진 비유 동성 소음(stationary noise) (Kim et al., 2017)과 믹싱하여 0, $3,6 \mathrm{~dB} \mathrm{SNR}$ 조건에서도 청능훈련을 시행할 수 있도록 하였 다. 따라서 소음을 제시하지 않는 조건과 세 가지의 소음 하 조 건(0, 3, $6 \mathrm{~dB} \mathrm{SNR})$, 총 4가지 듣기 조건에서 1,616 개의 음원을 각각 제시할 수 있도록 최종적으로 6,464 개의 문장 음원을 제 작하였다.

\section{3단계: 그림판 제작}

본 연구에서는 단어의 조합으로 생성한 문장 음원을 듣고 각 중심 단어에 해당하는 그림을 선택할 수 있도록 아동용 훈련 도구를 제작하였다. 이를 위해 전문 일러스트레이터가 테블렛 (CTL-490, Wacom, China)과 Clip Studio Paint Pro 소프트 웨어(CELSYS, Inc., Tokyo, Japan)를 사용하여 총 241개의 그 림을 제작하였으며, 2 명의 성인이 각 그림이 단어를 적절히 잘 나타내는지 확인하였다.

Appendix 2는 각 목록 내(list 1 6) 예시 문장 1개에 해당하 는 그림들을 보여준다. List 1 의 경우 훈련 전 듣고 맞추기를 위 한 연습 목록이므로 각 목표 단어에 해당하는 그림을 제작하 지 않고 문장의 의미에 해당하는 그림을 제작하였다. 예를 들 어 “원숭이가 빨간색 엉덩이를 가리킨다.”라는 문장 음원을 듣 고 아동이 “원숭이가 빨간색 엉덩이를 가리키는 그림”을 선택하 도록 그림판을 제작하였다. List 2에는 8개의 동물 단어와 8개 의 탈 것 단어가 포함되므로 총 16 개의 그림을 제작하였다. List 2의 예시 문장으로 "염소가 자동차를 탄다.”를 제시할 경우 총 16 개의 그림 보기 중 목표 단어인 “염소” "자동차”에 해당하는 그림을 선택할 수 있게 하였다. List 3 6 역시 같은 방식으로 그 림판을 구성하였다.

아동에 따라 그림의 개수가 너무 많을 경우 정답에 해당하 는 그림을 선택하기 어려울 수 있다. 훈련 시 전문가가 그림의 개수를 자유롭게 조절할 수 있도록 PowerPoint 2016 (Micro- soft Corp., Redmond, WA, USA)를 이용하여 최종 그림판을 구성하여 훈련 시 난이도 조절이 용이하게 하였다.

\section{4단계: 문장 음원의 자연성 및 그림판의 적절성 검증}

본 4단계(예비 실험)에서는 아동의 문장인지도를 측정하는 데 목적을 두기보다는 단어의 조합으로 생성한 문장 음원이 듣기 자연스러운지, 각 그림이 문장 내 단어를 적절히 잘 표현하고 있 는지 확인하는 데 목적을 두었다. 4.9 6.9세의 아동 4명(여 3, 남 1)이 예비 실험에 참여하였으며 아동 4명 모두 250 8,000 Hz 범 위 내 주파수별 청력이 양이 모두 $15 \mathrm{~dB} \mathrm{HL}$ 이하였다. 예비 실 험 당시 4명의 아동은 모두 유치원에 재원 중이었으며, 취학 전 아동의 수용언어 및 표현언어 발달 척도(Preschool ReceptiveExpressive Language Scale, PRES) (Kim, 2000) 검사 결과 모두 정상 범주 내에 속하였다.

예비 실험을 위해 아동의 정면으로부터 $1 \mathrm{~m}$ 떨어진 곳에 위 치한 스피커와 노트북(15N54; LG Electronics Inc., Seoul, Korea)을 통해 문장 음원을 제시하였다. 제시 강도는 일상 대 화음 레벨인 $45 \mathrm{~dB}$ HL이었으며 아동에게 조용한 상황에서(in quiet) 각 문장을 듣고 문장 내 단어에 해당하는 그림을 고르 게 하였다. List 1 은 연습의 목적으로 사용하였으며 list 2 6의 문장들은 실험을 위해 제시하였다.

예비 실험 결과, 4명의 아동 모두 조용한 상황에서 문장을 듣 고 단어를 고르는 데 어려움을 보이지 않았으나, 혼동된다고 이 야기한 몇 가지 그림은 모두 재제작하였다. Appendix 3는 수정 전 후 그림 예시를 보여주는데, 예를 들어 list 1 의 “오리”의 경 우 선이 흐려 잘 보이지 않아 보다 선이 잘 드러나게 수정하였 고 list 2의 “기차”의 경우 너무 짧아 기차로 보이지 않는다고 하 여 긴 기차가 되도록 수정하였다. List 5의 “하얀색 반지”와 “하 얀색 양말"의 경우 이에 맞도록 그림을 수정하였고, list 6의 “신 발”은 “부츠”와 혼동된다고 하여 “신발”에 가깝도록 그림을 재 제작하였다.

\section{5단계: 도구의 난이도 검증}

연구 대상

도구의 검증을 위해 25 명의 학령전기 아동이 참여하였고 아 동의 평균 연령은 4.7세(범위: 3.8 6.4세)였다. 연구 대상자는 경기도 수원에 위치한 지성 유치원 재원생이었으며, 승인을 받 고 실험을 진행하였다(\#HUGAUD439175). 실험 전 아동의 부 모에게 안내문을 전달하여 연구의 목적 및 절차에 대해 설명하 였고, 연구 참여에 동의를 한 부모의 아동을 대상으로 실험을 진행하였다.

대상 아동의 양이 모두 $250 \sim 8,000 \mathrm{~Hz}$ 이내 옥타브 단위의 
주파수별 순음청력역치가 $20 \mathrm{~dB} \mathrm{HL}$ 미만이었다. 본 연구에 참 여한 아동 모두 학령전기용 어음청각검사표인 한국 표준 학령 전기용 단음절어표(Korean Standard Monosyllabic Word Lists for Preschoolers) (Kim et al., 2008)를 이용하여 단어인지도 (Word Recognition Score)를 측정한 결과 $100 \%$ 의 단어인지도 를 보였다. 취학 전 아동의 수용언어 및 표현언어 발달 척도 (PRES) (Kim, 2000) 검사를 시행한 결과 대상 아동의 지능 지 수 및 언어 발달 연령 모두 정상 범주 내에 속하였다.

\section{도구의 검증 절차 및 연구 장비}

본 연구에서 제작한 훈련 도구의 난이도를 검증하기 위해 건 청 아동이 소음 하 상황에서도 훈련용 문장을 듣고 맞추는지 확인하였다. 아동의 청력검사 시 연간 보정을 실시한 청력검사 기(AD229b; Interacoustics, Middelfart, Denmark)와 헤드폰 (TDH-39P; Telephonics Corporation, Farmingdale, NY, USA) 을 사용하였다. 실험은 10 평 내외의 조용한 유치원 상담실에서 시행하였으며, 실험 장소의 소음을 1 분간 측정하였을 때(Sound Level Meter, TES-52A, TES Electrical Electronic Corp., Taipai, Taiwan) $50 \mathrm{~dB}$ LAeq 이하였다. 문장 음원은 노트북 (15N54, LG Electronics Inc.)과 아동의 정면 $1 \mathrm{~m}$ 앞에 위치한 컴퓨터 스피커(BR-Twiin Q; Britzinternational, Paju, Korea) 를 통해 약 $65 \mathrm{~dB} \mathrm{SPL}$ 의 강도로 문장을 제시하였다.

본 연구에서 듣기조건당 총 1,616 개의 문장 음원을 제작하였 으나, 학령전기 아동이 이를 모두 듣고 답하는 것은 불가능하 였다. 따라서 1,616 개의 문장을 무작위로 나누어 아동에게 제 시하되 각 아동이 모든 중심 단어를 들을 수 있게 하였다. 따라 서 아동은 각 소음 조건에서 약 70 개의 문장 $(1,616$ 개 문장/25 명 $=65$ 개 문장)을 듣고 그림판에서 문장 내 단어를 선택하였 다. 소음 조건의 순서는 무작위로 제시하였으며, 아동이 문장 을 듣고 그림을 옳게 고르지 못한 경우 피드백으로 2 3회 더
들려주었다. 반복 청취 후에도 목표 단어에 해당하는 그림을 선택하지 못한 경우 오반응으로 간주하였다. 문장인지도를 백 분율로 점수화 $(\%)$ 하기 위해 중심 단어의 정답률을 기준으로 하지 않고 문장 내 중심 단어를 한 개라도 틀리게 대답한 경우 오반응으로 간주하였다. 3 가지의 소음 하에서 문장을 들려주 고 도구를 검증하는 데 아동당 약 40 분가량 소요되었으며, 아 동이 원할 경우 실험 도중 휴식을 취할 수 있도록 하였다.

\section{결과 분석}

SPSS version 20.0 (IBM Corp., Armonk, NY, USA) 소프 트웨어를 이용하여 결과를 분석하였다. 그룹 내 독립 변수인 소음 조건(0, 3, $6 \mathrm{~dB} \mathrm{SNR})$ 과 문장 목록(list 1 6)에 따라 종속 변수인 문장인지도(\%)가 다른지 확인하기 위해 반복 측정된 이 원배치 분산분석을 실시하였다. 분석 시 Mauchly 구형성 가정 에 위배될 경우 Greenhouse-Geisser 수정된 자유도와 F값을 사용하였다. 추가로 Pearson 상관분석을 통해 각 목록의 평균 인지도와 아동의 연령 간 상관성을 확인하였고, 모든 통계 분 석은 유의 수준 0.05 를 기준으로 하였다.

\section{RESULTS}

0, 3, $6 \mathrm{~dB} \mathrm{SNR}$ 의 소음 상황에서 문장을 제시하고 문장인지 도를 측정하여 훈련 도구의 난이도를 측정하였다. Figure 1은 세 가지 소음 조건(0, 3, $6 \mathrm{~dB}$ SNR)에서 문장 목록에 따른(list 1 6) 평균 문장인지도를 보여준다. 듣기 조건과 목록별 결과를 살펴보면, 먼저 $0 \mathrm{~dB} \mathrm{SNR}$ 에서의 평균 문장인지도는 list 1 부터 6 까지의 순서대로 $100,100,98.8,99.8,97.1,34 \%$ 였다. $3 \mathrm{~dB}$ $\mathrm{SNR}$ 에서 측정한 평균 문장인지도는 list 1 부터 6 의 순서대로 $100,100,99.8,100,97,42 \%$ 였다. 마지막으로 $6 \mathrm{~dB}$ SNR에서 측정한 평균 인지도는 목록 순서대로 $100,100,99.8,100,96$,

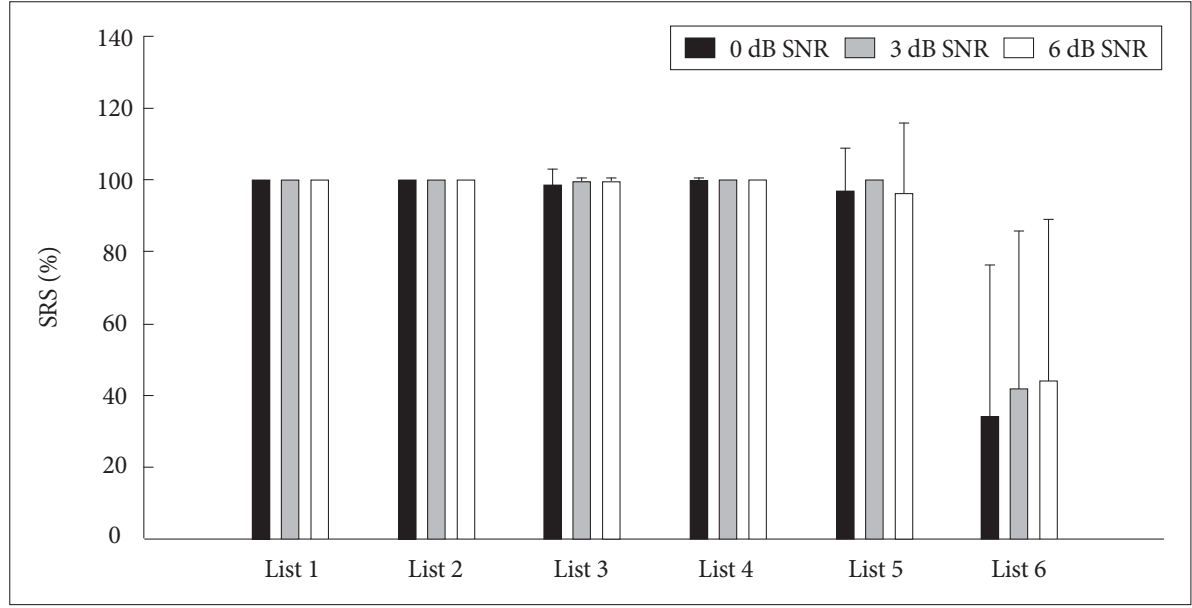

Figure 1. Mean SRS of each list (list 16) when evalauted at $0,3,6 \mathrm{~dB}$ SNRs. SRS: sentence recognition score. SNR: signal-to-noise ratio. 
44\%였다.

통계 분석 결과 문장 목록에 따라 문장인지도가 유의하게 달랐으나 $[\mathrm{F}(5,120)=47.98, p<0.05]$, 소음 조건 $(0,3,6 \mathrm{~dB}$ $\mathrm{SNR})$ 에 따라 문장인지도가 유의하게 다르지는 않았다 $[\mathrm{F}(1.33$, 32) $=1.85, p>0.05$. Bonferroni 대응비교 분석 결과 list 6 의 문장인지도가 나머지 문장 목록을 이용하여 측정한 문장인지 도에 비해 유의하게 낮았다. Figure 1을 통해 알 수 있듯이 list 6를 제외하고는 모든 소음 조건에서 $97 \%$ 이상의 높은 문장인 지도를 보였다. 그러나 list 6 의 경우 평균 $40 \%$ 의 인지도를 보였 다(표준편차: 42). 소음 조건과 문장 목록 간 이원 상호작용이 유의하지 않았으므로 $[\mathrm{F}(2.2,52.8)=2.35, p>0.05]$ 모든 조건 에서 list 6 를 제시하였을 때 저하된 인지도를 보였음을 알 수 있다. 각각의 듣기 조건에서의 list 6 를 제시하였을 때의 평균 문장인지도를 살펴보면 0,3,6 dB SNR의 순서대로 $34 \%$ (표준 편차: 42.4), 42\%(표준편차: 44), 44\%(표준편차: 45)였다. 즉, 모 든 소음 조건에서 list 6 의 인지도에 편차가 컸는데, 그 이유는 25 명의 아동 중 일부가 list 6 의 문장 인지 시 90 100\%의 인지 도를 보인 반면, 일부 아동은 $0 \%$ 의 인지도를 보였기 때문이다.

List 1 부터 5의 경우 문장 내에 2개 혹은 3개의 중심 단어를 포함하고 있는 반면, list 6 의 문장에는 4 개의 중심 단어가 포함 되어 있어(예: “엄마가 시장에서 장갑과 가방을 산다.") 아동이 문장 내 단어 4 개를 모두 기억하고 4 개의 그림을 선택하여야 했다(Appendix 1). 본 연구에 참여한 25명 아동 간 최대 24개 월 이상 연령 차이가 났으므로(연령 범위는 3.8 6.4세), list 6를 듣고 저하된 인지도를 보인 것이 나이와 관련성이 있는지 Pearson 상관 분석을 시행하였다. 분석 결과 각 소음 조건에서 list 6를 제시하고 측정한 문장인지도는 아동의 연령과 유의한 관 련성이 없었다 $(p>0.05)$. 모든 소음 조건에서 list 6 의 인지도 에 편차가 컸으므로 각 조건 간 인지도가 서로 관련성을 가지 는지 상관 분석을 시행한 결과, 모든 조건 간 list 6 의 문장인지 도가 유의한 상관성을 보였다(Pearson 상관계수: 0.85 0.99, $p$ $<0.05)$. 따라서 $6 \mathrm{~dB}$ SNR에서 list 6 를 인지하는 것이 어려웠 던 아동은 아동의 나이에 상관없이 $3 \mathrm{~dB}$ SNR과 $0 \mathrm{~dB}$ SNR에 서도 어려움을 보였음을 확인하였다.

\section{DISCUSSIONS}

본 연구에서는 문장을 듣고 그림 보기에서 문장 내 단어를 고르는(closed-set) 청능훈련 도구를 개발하였다. 아동용 청능 훈련에 사용할 도구이므로 학령전기 아동의 어휘에 관한 문헌 에서 단어를 수집하여 문장을 구성하였고 문장 내 단어를 조 합하여 총 1,616 개의 문장 음원을 제작하였다. 임상에서 다양 한 듣기 조건에서 훈련이 가능하도록 $(0,3,6 \mathrm{~dB} \mathrm{SNR})$ 문장을
소음과 믹싱하였고, 문장 내 단어에 해당하는 그림을 제작하였 다. 예비 실험에서 확인한 문제점을 수정 보완하여 PowerPoint 를 통해 최종 그림판을 구성하였으며, 건청 아동 25 명을 대상 으로 소음 상황에서 문장인지도를 측정하여 훈련 도구의 난이 도를 검증하였다.

소음 하 문장인지도를 측정한 결과, 학령전기 건청 아동 모 두 $0,3,6 \mathrm{~dB} \mathrm{SNR}$ 듣기 조건에 상관없이 중심 단어 2 3개를 듣고 문장을 인지하는 데 크게 어려움을 보이지 않았다. 그러나 중심 단어 4 개를 포함하는 list 6 의 경우 평균 $40 \%$ 의 저하된 인지도를 보였고 대상자 간 편차 또한 컸다. 25 명의 건청 아동 중 6명의 아동은 list 6의 문장을 듣고 $97 \sim 100 \%$ 의 인지도를 보 였던 반면, 11 명은 $0 \%$ 의 인지도를 보였다. 위의 대상자 정보에 서 알 수 있듯이 아동 모두 건청이었고 조용한 상황에서 $100 \%$ 의 단어인지도를 보였으며, 연령에 맞는 언어 발달을 보이고 있 었다. 상관분석 결과 list 6 의 인지도는 아동의 연령과 유의한 상관성을 보이지 않았다. 따라서 아동의 나이가 어려 list 6 의 문 장을 인지하는 데 더 어려움을 보였다기보다는, 아동의 기억력 및 집중력이 문장 내 중심 단어 4 개를 모두 기억하고 인지하는 능력에 영향을 미쳤을 것으로 추정한다. 본 연구에서는 아동의 청력, 언어 발달 단계가 정상 범위인지 확인하였으나 아동 개개 인의 작업기억 능력을 측정하지는 않았다. Igualada et al.(2017) 은 106명의 학령전기 아동(만 3 5세)을 대상으로 연령별 단어 회상(word recall) 능력을 측정한 결과, 평균적으로 회상 가능 한 단어의 개수가 2 4개였다고 보고하였다. 따라서 학령전기 난청 아동에게는 3 개 이하의 중심 단어를 포함하는 문장 목록 (list 2 5)을 이용하여 훈련을 시행하고, 4개 이상의 중심 단어 를 포함하는 list 6 의 경우 학령기 난청 아동 및 청소년에게 활 용하는 것이 더 적절하겠다.

본 연구 결과 3 개 이하의 중심단어를 포함하는 한, $0,3,6$ $\mathrm{dB} \mathrm{SNR}$ 의 소음 조건은 건청 아동의 문장인지도에 크게 영향 을 주지 않았다. 그러나 이와 같은 소음 상황이 난청 아동에게 는 듣고 인지하는 데 어려운 조건일 수 있다(Park \& Lee, 2005; Seo \& Lim, 2007). 청능훈련의 경우 대상자가 좌절감이 나 지겨움을 느끼지 않고 훈련에 참여할 수 있도록 하는 것이 중요하므로 아동의 듣기 및 인지 능력을 잘 파악하여 훈련의 난이도 등을 잘 결정하는 것이 중요하겠다. 이제까지 청능훈련 을 시행하고 훈련 효과를 입증한 국내외 연구 대부분이 청능사 등의 전문가의 도움을 통해 훈련을 진행하였다(Jo et al., 2013; Kim \& Lee, 2010; Lee et al., 2016a; Yeo et al., 2014). 향후 난 청 성인 본인 혹은 난청 아동의 부모가 집에서도 활용할 수 있 으려면 스마트 기기를 이용한 앱의 개발이 필요할 것으로 생각 한다(Yu et al., 2014). Lee(2016)에 의하면 대부분의 인공와우 아동 부모가 앱을 이용한 청각재활 콘텐츠가 자녀의 청각 수행 
력을 발달시킬 수 있을 거라 인식하고 있음을 보고하였다. 다만 스마트 기기를 청능훈련에 이용할 경우 부모 혹은 전문가와 직 접적인 상호작용을 할 기회가 줄어들고 이것이 부정적인 영향 을 미칠 수 있으므로 이를 고려하여 앱 혹은 소프트웨어를 활 용하는 청각재활 콘텐츠를 개발하는 것이 중요하겠다. 또한 성 인에 비해 아동이 주관적으로 선호하는 훈련 방법에 대한 연구 가 부족한 편이므로 아동의 청능훈련 효과에 영향을 줄 수 있 는 다양한 변수들에 대한 연구가 지속되어야겠다.

요약하면 본 연구에서는 훈련의 난이도 조절을 위해 최소 2 개부터 최대 4개의 중심 단어를 포함하는 문장 목록을 구성하 였고, 그림판을 제작하여 아동이 흥미를 가지고 훈련에 참여할 수 있도록 하였다. 소음 하에서 본 연구에서 개발한 청능훈련 도구의 난이도를 검증한 결과, 4개의 중심 단어로 구성된 list 6 를 제외하고 $0,3,6 \mathrm{~dB} \mathrm{SNR}$ 모든 조건에서 문장 내 단어를 기 억하고 인지하는 데 어려움을 보이지 않았다. 본 연구에서 개 발한 보기가 있는 아동용 훈련 도구는 문장 내 보기의 개수를 조절하거나 듣기 조건을 변경하여 난이도를 조정하는 것이 용 이하다는 장점이 있다. 도구의 특성상 문장을 집중하여 듣고 각 문장에 포함된 중심 단어를 기억하고 선택해야 하므로 아동 의 단기기억력 및 주의집중력을 개선하는 데에도 긍정적인 역 할을 하리라 기대한다.

\section{중심 단어 : 아동 청능훈련·청각재활·난청 아동.}

\section{Acknowledgments}

본 연구에 참여해 주신 아동 참여자들과 음원 및 그림 제작을 위 해 애써주신 이동운, 김나경 연구원과 오지혜 일러스트레이터에게 감사드립니다. 마지막으로 실험에 동의해주신 아동 부모님들과 데이 터 수집을 위해 수고해주신 유치원 관계자 분들께 감사드립니다.

\section{REFERENCES}

Ahn, P. H. \& Lee, K. (2016). Development of environmental sounds for auditory training. Audiology and Speech Research, 12(2), 82-88.

Baek, S. S. \& Lee, J. H. (2016). Development of crossword puzzles for auditory training. Audiology and Speech Research, 12(2), 103-108.

Cameron, S. \& Dillon, H. (2011). Development and evaluation of the LiSN and learn auditory training software for deficit-specific remediation of binaural processing deficits in children: Preliminary findings. Journal of the American Academy of Audiology, 22(10), 678-696.

Cha, J. E., Kim, J. M., Kim, S. J., Yoon, M. S., \& Chang, M. S. (2014). Substantives in the vocabulary of typically developing young children. Communication Sciences and Disorders, 19(4), 430-436.

Chang, H. J., Jeon, H. S., Shin, M. S., \& Kim, H. J. (2013). A study on selection of basic vocabulary for infants and toddlers. Journal of SpeechLanguage and Hearing Disorders, 22(3), 169-187.

Chang, H. J., Jeon, H. S., Shin, M. S., \& Kim, H. J. (2014). Study on selection of basic vocabulary for elementary school students: Focused on basic vocabulary in the lower grades. Journal of Speech-Language and Hearing Disorders, 23(1), 157-170.

Chang, S. \& Lee, J. (2016). Development of auditory training tool for adults using sentences. Audiology and Speech Research, 12(2), 89-96.

Choi, W. J., Oh, S. H., \& Bahng, J. (2017). Efficacy of music training on speech recognition and working memory in children wearing cochlear implants. Audiology and Speech Research, 13(1), 70-77.

Ferguson, M. \& Henshaw, H. (2015). How does auditory training work? Joined-up thinking and listening. Seminars in Hearing, 36(4), 237-249.

Henshaw, H. \& Ferguson, M. A. (2013). Efficacy of individual computerbased auditory training for people with hearing loss: A systematic review of the evidence. PloS One, 8(5), e62836.

Igualada, A., Esteve-Gibert, N., \& Prieto, P. (2017). Beat gestures improve word recall in 3-to 5-year-old children. Journal of Experimental Child Psychology, 156, 99-112.

Ingvalson, E. M., Young, N. M., \& Wong, P. C. (2014). Auditory-cognitive training improves language performance in prelingually deafened cochlear implant recipients. International Journal of Pediatric Otorhinolaryngology, 78(10), 1624-1631.

Jo, Y. Y., Bahng, J., \& Lee, J. H. (2013). Case study of auditory training for an elderly hearing aid user. Audiology, 9(2), 190-194.

Kim, H. G. \& Lee, K. W. (2010). Effects of word recognition score as a function of auditory training terms for elderly hearing impaired with hearing aid. Audiology, 6(2), 159-163.

Kim, J. \& Yoon, J. (2016). Development of Korean aural rehabilitation for infants. Audiology and Speech Research, 12 (Suppl 1), S41-S46.

Kim, J. S., Lim, D., Hong, H. N., Shin, H. W., Lee, K. D., \& Hong, B. N. (2008). Development of Korean standard monosyllabic word lists for school aged children (KS-MWL-S) and preschoolers (KS-MWL-P). Audiology, 4(2), 141-160.

Kim, N. K., Yi, D., Bahng, J., \& Lee, J. H. (2017). Study on the reliability and the validity for the sentence-in-noise scores at the fixed signal-tonoise ratios. Audiology and Speech Research, 13(1), 62-69.

Kim, Y. T. (2000). Content and reliability analyses of the preschool receptive-expressive language scale (PRES). Journal of Communication Sciences and Disorders, 5(1), 1-25.

Lee, J. H., Lee, S. G., \& Bahng, J. (2016a). Case study of auditory training for long-term users of hearing aids with poor word recognition. Audiology and Speech Research, 12(3), 190-194.

Lee, J. W., Yi, D. W., Lee J., \& Lee, J. H. (2016b). A preliminary evaluation of multiple-choice sentences developed for auditory training. Audiology and Speech Research, 12(2), 97-102

Lee, Y. (2016). Parental current practice and needs in smart device applications for children with cochlear implants. Audiology and Speech Research, 12(4), 269-279.

Lim, E. H. \& Bahng J. (2016). Preliminary study for development of auditory training tool using story and question. Audiology and Speech Research, 12(2), 109-114

Loo, J. H. Y., Rosen, S., \& Bamiou, D. E. (2016). Auditory training effects on the listening skills of children with auditory processing disorder. Ear and Hearing, 37(1), 38-47.

Melo, Â. D., Costa, M. J., Garcia, M. V., Filha, V. A. V. D. S., \& Biaggio, E. P. V. (2015). The use of software on auditory training in children: Theoretical review. Revista CEFAC, 17(6), 2025-2032.

Oh, J. H., Cha, J. E., Yoon, M. S., Kim, J. M., \& Chang, M. S. (2014). Predicates in the vocabulary of typically developing preschoolers. Coтmunication Sciences and Disorders, 19(3), 274-284.

Oh, S. H. (2016). An overview of auditory training for cochlear implant recipients. Audiology and Speech Research, 12(Suppl 1), S47-S50.

Park, S. H. \& Lee, D. J. (2005). Aural rehabilitation of children with cochlear implants. Audiology, 1(1), 90-93.

Rochette, F. \& Bigand, E. (2009). Long-term effects of auditory training in severely or profoundly deaf children. Annals of the New York Academy of Sciences, 1169(1), 195-198.

Rochette, F., Moussard, A., \& Bigand, E. (2014). Music lessons improve auditory perceptual and cognitive performance in deaf children. Frontiers in Human Neuroscience, 8, 488.

Seo, Y. R. \& Lim, D. (2007). Application of musical therapy for aural rehabilitation of children with cochlear implants. Audiology, 3(2), 116-121. Sullivan, J. R., Thibodeau, L. M., \& Assmann, P. F. (2013). Auditory training 
of speech recognition with interrupted and continuous noise maskers by children with hearing impairment. The Journal of the Acoustical Society of America, 133(1), 495-501.

Talebi, H., Moossavi, A., Lotfi, Y., \& Faghihzadeh, S. (2015). Effects of vowel auditory training on concurrent speech segregation in hearing impaired children. The Annals of Otology, Rhinology, and Laryngology, 124(1), 13-20

Yeo, S., Bahng, J., \& Lee, J. H. (2014). Efficacy of auditory training using sentences in noise for hearing aid users. Audiology, 10(1), 65-75.

Yoo, J. K. \& Lee, K. M. (2011). Multimedia auditory training design for hearing-impaired children. Journal of Korea Computer Game Society,
24(2), 53-62.

Yoon, H. B. \& Hwang, D. S. (2005). A review study for development of auditory training program to hearing-impaired children. Journal of Special Children Education, 7(3), 269-289.

Yoon, J., Kim, J., \& Park, H. (2016). Early auditory rehabilitation of an infant with unilateral profound hearing loss: A case study. Audiology and Speech Research, 12(2), 115-125.

Yu, J., Chun, H., Song, C. G., \& Han, W. (2014). Case study of speech perception enhancement in hearing-impaired adult by auditory training program of mobile device. Audiology, 10(2), 158-168. 


\section{APPENDICES}

Appendix 1. Key Words in Each Sentence for List 1-6

\begin{tabular}{|c|c|c|c|}
\hline $\begin{array}{l}\text { Sentence } \\
\text { list no. }\end{array}$ & Sentence (key words underlined) & $\begin{array}{l}\text { No. of } \\
\text { key words }\end{array}$ & $\begin{array}{c}\text { Possible no. of sentences } \\
\text { based on key words }\end{array}$ \\
\hline List 1 (practice) & $\begin{array}{l}\text { 원숭이가 빨간색 엉덩이를 가리킨다 } \\
\text { 오리가 노란색 입을 가리킨다 } \\
\text { 도마뱀이 초록색 꼬리를 가리킨다 } \\
\text { 캥거루가 주황색 귀를 가리킨다 } \\
\text { 돼지가 분홍색 코를 가리킨다 } \\
\text { 오징어가 하얀색 다리를 가리킨다 } \\
\text { 고릴라가 검정색 팔을 가리킨다 } \\
\text { 코알라가 갈색 눈을 가리킨다 }\end{array}$ & 2 & $8(8 \times 1)$ \\
\hline List 2 & $\begin{array}{l}\text { 염소가 자동차를 탄다 } \\
\text { 기린이 배를 탄다 } \\
\text { 타조가 기차를 탄다 } \\
\text { 두더지가 자전거를 탄다 } \\
\text { 병아리가 비행기를 탄다 } \\
\text { 소가 미끄럼틀을 탄다 } \\
\text { 여우가 그네를 탄다 } \\
\text { 얼룩말이 시소를 탄다 }\end{array}$ & 2 & $64(8 \times 8)$ \\
\hline List 3 & $\begin{array}{l}\text { 강아지가 빨간색 } 1 \text { 을 가리킨다 } \\
\text { 나비가 주황색 } 2 \text { 를 가리킨다 } \\
\text { 다람쥐가 노란색 } 3 \text { 을 가리킨다 } \\
\text { 사자가 초록색 } 4 \text { 를 가리킨다 } \\
\text { 원숭이가 파란색 } 5 \text { 를 가리킨다 } \\
\text { 토끼가 보라색 } 6 \text { 을 가리킨다 } \\
\text { 코끼리가 검정색 } 7 \text { 을 가리킨다 } \\
\text { 하마가 하얀색 } 8 \text { 을 가리킨다 }\end{array}$ & 3 & $512(8 \times 8 \times 8)$ \\
\hline List 4 & $\begin{array}{l}\text { 고양이가 하얀색 우유와 노란색 바나나를 먹는다 } \\
\text { 거북이가 보라색 포도와 검정색 과자를 먹는다 } \\
\text { 부엉이가 파란색 주스와 초록색 키위를 먹는다 } \\
\text { 악어가 빨간색 사과와 주황색 케이크를 먹는다 }\end{array}$ & 3 & $64(4 \times 4 \times 4)$ \\
\hline List 5 & $\begin{array}{l}\text { 하얀색 치마를 한 개 찾았다 } \\
\text { 초록색 가방을 두 개 찾았다 } \\
\text { 파란색 공을 세 개 찾았다 } \\
\text { 검은색 접시를 네 개 찾았다 } \\
\text { 노란색 바지를 다섯 개 찾았다 } \\
\text { 보라색 양말을 여섯 개 찾았다 } \\
\text { 빨간색 반지를 일곱 개 찾았다 }\end{array}$ & 3 & $343(7 \times 7 \times 7)$ \\
\hline List 6 & $\begin{array}{l}\text { 엄마가 시장에서 장갑과 가방을 산다 } \\
\text { 아빠가 백화점에서 신발과 양말을 산다 } \\
\text { 할머니가 마트에서 빵과 사탕을 산다 } \\
\text { 오빠가 문방구에서 풍선과 공을 산다 } \\
\text { 언니가 슈퍼에서 공책과 연필을 산다 }\end{array}$ & 4 & $625(5 \times 5 \times 5 \times 5)$ \\
\hline
\end{tabular}


Appendix 2. Picture Examples Matched to Each Sentence

\begin{tabular}{|c|c|c|}
\hline Sentence list no. & Pictures examples & Sentences \\
\hline $\begin{array}{c}\text { List } 1 \\
\text { (practice) }\end{array}$ & & $\begin{array}{l}\text { 원숭이가 빨간색 엉덩이를 } \\
\text { 가리킨다. }\end{array}$ \\
\hline List 2 & & 염소가 자동차를 탄다. \\
\hline List 3 & & 강아지가 빨간색 1 을 가리킨다. \\
\hline List 4 & & $\begin{array}{l}\text { 고양이가 하얀색 우유와 노란색 } \\
\text { 바나나를 먹는다. }\end{array}$ \\
\hline List 5 & & 하얀색 치마를 한 개 찾았다. \\
\hline List 6 & & 엄마가 시장에서 장갑과 가방을 \\
\hline
\end{tabular}


Appendix 3. Picture Examples Before and After Modification

\begin{tabular}{lll}
\hline Sentence list no. & Before modification \\
List 1 & & \\
(practice) & &
\end{tabular}

